\title{
ELECTRON-BEAM MELTING OF INGOTS OF TIAI SYSTEM INTERMETALLICS
}

\author{
S.V.Akhonin ${ }^{1}$, V.A.Berezos ${ }^{1}$, A.Yu.Severyn ${ }^{1}$ \\ ${ }^{1}$ E.O. Paton Electric Welding Institute of the National Academy of Sciences of Ukraine, 11 Kazymyr Malevych St., Kyiv 03150 Ukraine
}

Keywords: electron beam melting, ingot, mathematical modelling, titanium aluminide, alloying elements, structure

\begin{abstract}
$\underline{\text { Abstract }}$
Performance of scientific-technical researches at the E. O. Paton Electric Welding Institute of the NAS of Ukraine have been directed on development of technology for manufacture of titanium aluminide -based alloys using the method of electron-beam melting (EBM). The mathematical models of heat state and evaporation of alloying elements in EBM were developed. The results of calculations of heat state using the mathematical model allowed determining a dependence of depth of liquid pool on different melting rates. The mathematical models of processes of evaporation in EBM of titanium aluminide ingots were used for plotting the nomograms, which help to determine the necessary content of alloying element of the alloy in the initial charge for acquiring the necessary concentration of this element in ingot at set technological parameters of melting.
\end{abstract}

In scopes of designed mathematical models there were investigated different technological modes of electron-beam melting of ingots based on titanium aluminide. The optimum EBM modes, at which a solidification front approaches to flat, were determined. At that, more uniform distribution of the additives on ingot section and volume is provided as well as level of stressed state is reduced.

The works were carried out on manufacture of titanium aluminide based-ingots with addition of refractory as well as volatile alloying elements. Composition and structure of produced ingots were examined. It is shown that electron-beam melting allows getting chemically homogeneous ingots based on titanium aluminide and is a perspective method for production of such class materials.

\section{$\underline{\text { Introduction }}$}

Development of aircraft and automotive industry, power and chemical machine building promotes the rise of requirements to metallic materials allowing achievement of part working characteristics. Therefore, now different countries carry out the works on development of new perspective alloys with high temperature-resistance and thermal stability, which could provide long-term operation of parts at high temperatures [1-4]. The alloys based on TiAl system intermetallics are referred to such materials. This type of structural materials has a whole series of unique properties, i.e. low density, relatively high melting temperature, high elasticity modulus, resistance to oxidation and burning-up, high specific heat resistance etc. [5,6]. However, low ductility of titanium intermetallics under normal conditions and sensitivity to surface defects complicate their technological treatment and are the main obstacle for wide commercial application.

Rise of mechanical properties under normal conditions and increased temperatures can be reached by such methods as multi-component alloying with refractory elements as well as via structure refinement at melting stage as well as in deformation treatment [7].

In manufacture of ingots using known commercial metallurgical methods, an additional reason for reduction of technological ductility of these materials is coarse-grain structure, chemical inhomogeneity, gas porosity that can result in fracture of materials at further deformation treatment.

A new method of production of TiAl system intermetallics is electron beam melting (EBM), which has a series of indisputable advantages, namely possibility of charge remelting in any form; division of process of charge melting and solidification of ingot; high density of input energy; easy control and regulation of technological parameters $[8]$.

However, EBM method has some disadvantages related with loss in melting of alloying elements with high vapor pressure. In order to eliminate this disadvantage it is possible to add foundry alloys and compounds with lower vapor pressure into a charge composition. For production of quality homogeneous ingot it is reasonable to determine technological parameters of melting using mathematical modelling of the processes of evaporation and solidification in EBM.

E. O. Paton Electric Welding Institute of the NAS of Ukraine has carried scientific-technological researches directed on development of technology for production of alloys based on intermetallics of TiAl system using EBM.

A mathematical model of ingot solidification in EBM [8] was developed at the E. O. Paton Electric Welding Institute. This mathematical model allows obtaining distribution of temperatures in ingot at any moment of time, and, respectively, configuration of liquid pool and zone of liquid-solid state of metal depending on technological parameters of electron beam melting, i.e. process efficiency, periodicity of melt pouring into mould and power of electron beam heating.

In the scopes of built mathematical model we investigated the dependence of heat state of ingot in electron beam melting on melting efficiency. Calculations of formation process of $165 \mathrm{~mm}$ ingot of titanium aluminide alloy in EBM were carried out. The following technological parameters of melting, namely power of electron beam heating in the mould $14 \mathrm{~kW}$ and efficiency of melting process varying in $30-50 \mathrm{~kg} / \mathrm{h}$ limits were used.

Figure 1 shows the calculation temperature fields of ingot of titanium aluminide alloy for different melting rates within the mathematical model.
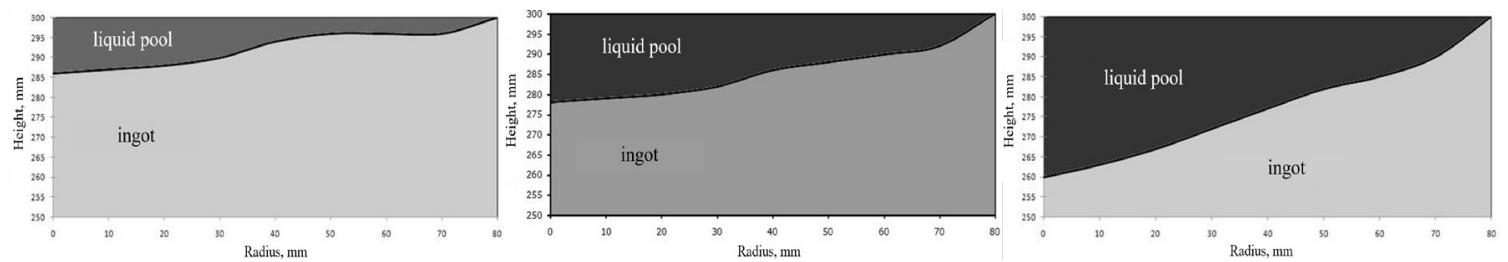

Figure1. Temperature fields of ingot for different rate of melting: $a-30 \mathrm{~kg} / \mathrm{h} ; \mathrm{b}-40 \mathrm{~kg} / \mathrm{h} ; \mathrm{c}-50 \mathrm{~kg} / \mathrm{h}$

It was determined a dependence of liquid pool depth in $165 \mathrm{~mm}$ diam. titanium aluminide ingot on melting rate (Figure 2). 


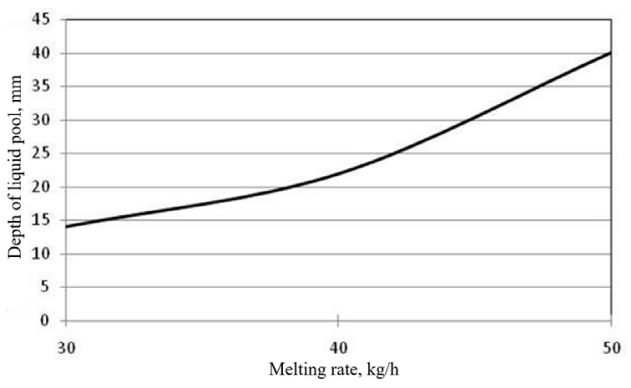

Figure 2. Dependence of liquid pool depth of rate of electron beam melting of $165 \mathrm{~mm}$ diam. titanium aluminide ingot

At melting process efficiency $30 \mathrm{~kg} / \mathrm{h}$ the depth of liquid pool makes $14 \mathrm{~mm}$ and that for $50 \mathrm{~kg} / \mathrm{h}$ is $40 \mathrm{~mm}$. The minimum liquid pool depth in the mould [9] should be provided in order to form fine grain structure of ingot.

Thus, different technological modes of electron beam melting of titanium aluminide ingots were investigated in scope of the developed mathematical models. The optimum modes of EBM were determined, at which a solidification front approaches to flat, that should promote formation of fine grain structure in the ingot.

A mathematical model of processes of evaporation of aluminum and other alloying components in EBM [10] was developed for determination of technological modes of production of intermetallic ingots of TiAl system.

Calculations of evaporation under EBM conditions for Ti-29Al-12Nb-3Cr- $3 \mathrm{Zr}$ (wt.\%) alloy were carried in scope of the mathematical model. They allow obtaining the dependence of content of aluminum, chromium, niobium and zirconium in the $165 \mathrm{~mm}$ titanium aluminide ingot on melting rate at different content of alloying elements in the initial charge (Figure 3).
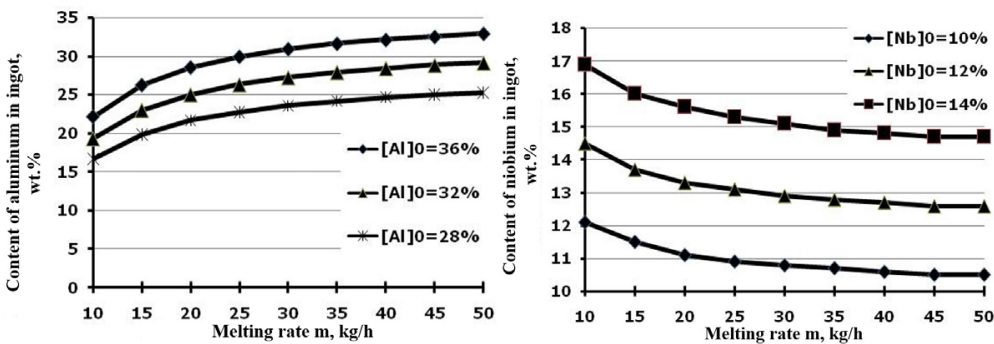

Figure 3. Dependence of content of alloying element in ingot of titanium aluminide based alloy on melting rate $m$ at different content of this element in remelted charge.

Based on the calculations using mathematical model there were also built the dependencies of content of alloying components of TiAl system intermetallic in the produced EBM ingot on their concentration in the initial charge at process efficiency $30 \mathrm{~kg} / \mathrm{h}$ (Figure 4). Obtained diagrams allows determining the necessary content of the alloying element of the alloy in the initial charge for getting required concentration of this element in the ingot at set melting rate.

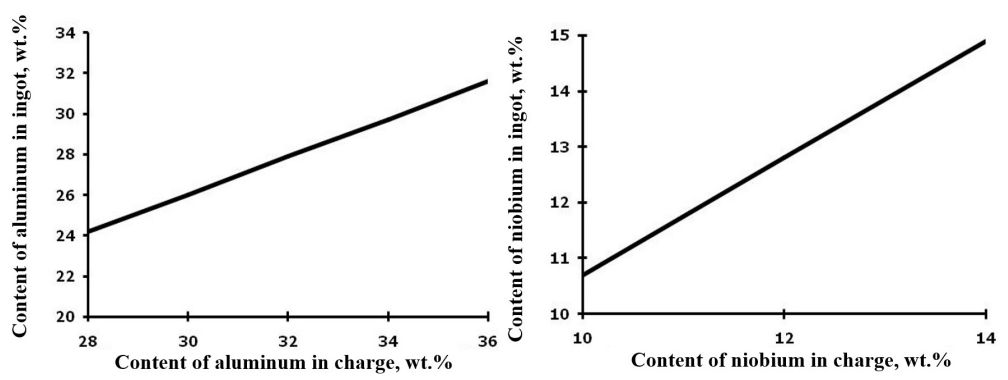

Figure 4. Dependence of content of aluminum (a) and niobium (b) in ingot of two-phase titanium aluminide on content of elements in initial charge at melting rate $30 \mathrm{~kg} / \mathrm{h}$

Thus, the developed mathematical model of the processes of evaporation of alloying elements from titanium alloys in cold hearth electron beam melting allows determining the dependencies of alloying element concentration in the ingot on technological parameters of melting and content of alloying elements in the initial charge as well as predicting composition of the melted ingots of TiAl system intermetallics and can be used for production of the ingots of necessary composition.

The works on production of ingots of alloys based on TiAl system intermetallics with addition of refractory as well as highly volatile alloying elements have been carried out.

g-TiAl has a series of positive characteristics, i.e. low specific weight, increased elasticity modulus, good heat resistance and high oxidation resistance at $600-800{ }^{\circ} \mathrm{C}$. The best combination of strength and ductility properties is reached in g-TiAl with small grain size [11].

Therefore, based on carried calculations in scope of the mathematical model the works were carried out in order to investigate the possibility of production of g-TiAl ingots of set composition and with favorable structure using EBM.

Melting of Ti-47Al-2Nb-1.5Cr ingot was carried out in accordance with calculated power and configuration of heating of its edge in the mould. At that alloying elements with high vapour pressure, chromium and aluminum, were charged taking into account evaporation losses.

As a result of carried experimental melts $165 \mathrm{~mm}$ diam. ingot was obtained (Figure 5). The results of chemical analysis are given in Table 1. Microsegregation in longitudinal as well as transverse directions is not observed. The average deviation of values of aluminum content made 0.4 wt. $\%$ and chromium and niobium were 0.2 wt. $\%$. 


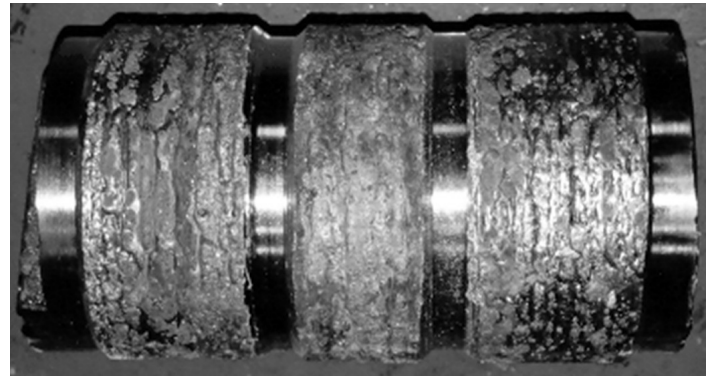

Figure 5. $165 \mathrm{~mm}$ diam. ingot Ti-47Al-2Nb-1.5Cr

Table 1. Composition of EBM g-titanium aluminide ingot

\begin{tabular}{|c|c|c|c|c|}
\hline \multirow{2}{*}{ Place of sampling } & \multicolumn{4}{|c|}{ Content of elements, at. $\%$} \\
\hline & $\mathrm{Ti}$ & $\mathrm{Al}$ & $\mathrm{Cr}$ & $\mathrm{Nb}$ \\
\hline Top & 49.6 & 46.5 & 1.3 & 2.1 \\
\hline Middle & 50.3 & 46.1 & 1.3 & 1.9 \\
\hline Botton & 49.7 & 46.5 & 1.3 & 2.1 \\
\hline \multicolumn{5}{|l|}{ Along radius } \\
\hline $1 / 4$ & 50.2 & 45.7 & 1.5 & 1.9 \\
\hline $1 / 2$ & 51.0 & 44.6 & 1.5 & 1.9 \\
\hline $3 / 4$ & 49.6 & 47.1 & 1.4 & 2.0 \\
\hline
\end{tabular}

The ingot microstructure (Figure 6$)$ conventionally can be divided on three zones, namely central ( $0-1 / 3$ of ingot radius), middle (1/3-5/6 of ingot radius) and peripheral (5/61 of radius). The central zone consists of virtually equiaxial grains of $3-5 \mathrm{~mm}$, average represents itself crystallites elongated along the radius of ingot and in the peripheral there are directed crystallites together with equiaxial grains $(<1 \mathrm{~mm})$.
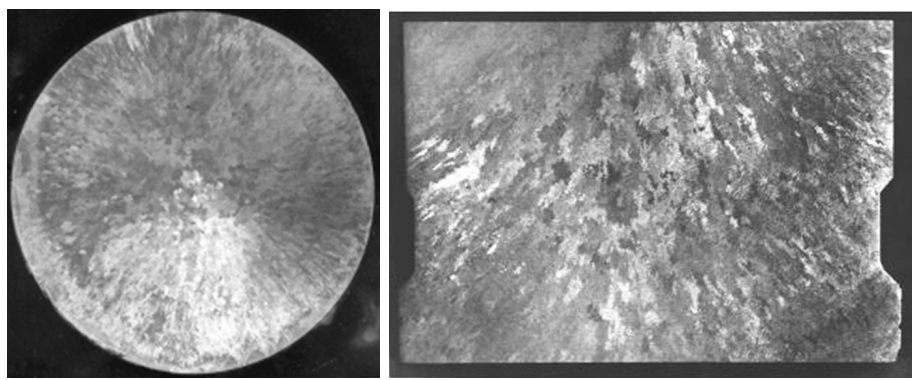

Figure 6. Microstructure of $165 \mathrm{~mm}$ diam. Ti-47Al-2Nb-1.5Cr ingot: a - cross section, $b$ - longitudinal section

Microstructure of ingot metal is typical for alloys based on g-TiAl (Figure 7). In the central part of the ingot there is grain dendrite structure, on the periphery it is dendrite. Inside grains the structure is lamellar consisting of $\mathrm{a}_{2} / \mathrm{g}$ plates.

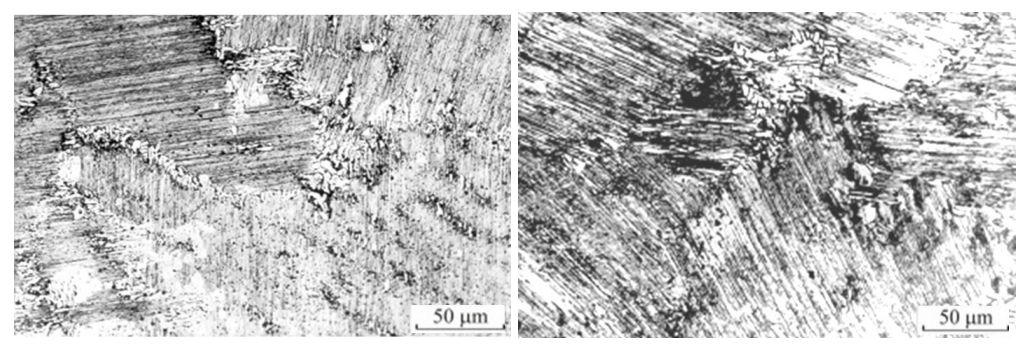

Figure 7. Microstructure of Ti-47Al-2Nb-1.5Cr: a - ingot center, $b$ - ingot periphery

Thus, the results of carried investigations indicate the perspectives of EMR method application for production of ingots of titanium alloys based on g-TiAl.

In order to solve a problem of addition of refractory elements, E. O. Paton Electric Welding Institute of the NAS of Ukraine carried the works on mastering the EBM technology of alloys based on TiAl intermetallics containing niobium, molybdenum, tungsten and zirconium.

$\mathrm{Ti}_{2} \mathrm{AlNb}$ group intermetallic alloys have the most favorable combination of mechanical properties, i.e. high strength and ductility characteristics, high temperature and heat resistance [12].

The alloy of the next composition Ti-12Al-40Nb-1Mo-2W-0.5Zr (wt.\%) was taken for experimental melts. Presence in the alloy composition of refractory alloying elements, niobium and tungsten, and element with high vapour pressure, namely aluminum, does not allow obtaining quality and chemically homogeneous ingot per one remelt since there is intensive evaporation of aluminum already at stage of charge melting. Moreover, addition of pure tungsten in form of pieces is sufficiently difficult in EBM since tungsten has not been completely melted at charge melting stage and there is a possibility of pieces entering into the ingot that is unallowable. For solution of this problem and addition of niobium, tungsten and other alloying elements as a foundry alloy commercial alloy Nb-2Mo- $2 \mathrm{~W}-\mathrm{Zr}$ was used. 
In order to provide chemical homogeneity the ingots were produced by double remelting. The first remelting was carried out with addition of refractory alloying elements without aluminum. At the second remelting aluminum was added.

The results of chemical analysis of produced experimental ingot (Figure 8) showed uniform distribution of alloying elements along the ingot length (Table 3).
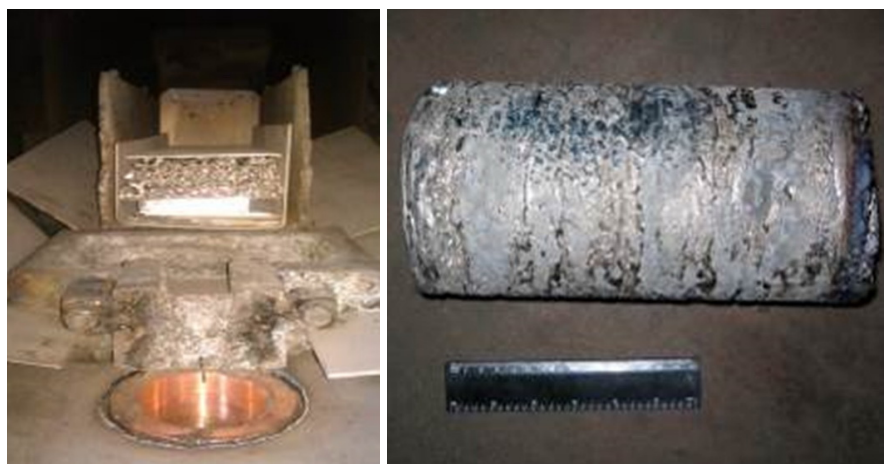

Figure 8. Initial charge for production of $\mathrm{Ti}_{2} \mathrm{AlNb}$ intermetallic (a) and ingot $\mathrm{Ti}_{2} \mathrm{AlNb}(\mathrm{b})$

Table 3. Composition of ingot of $\mathrm{Ti}_{2} \mathrm{AINb}$ system intermetallic with high content of refractory elements.

\begin{tabular}{||c||c|c|c|c||c||c||}
\hline \multirow{2}{*}{ Sampling place } & \multicolumn{6}{c||}{ Content of elements, wt.\% } \\
\cline { 2 - 7 } & $\mathrm{Al}$ & $\mathrm{Nb}$ & $\mathrm{Mo}$ & $\mathrm{W}$ & $\mathrm{Zr}$ & $\mathrm{Ti}$ \\
\hline \hline Top & 10.9 & 41.8 & 0.6 & 1.3 & 0.6 & \\
\hline Middle & 11.8 & 40.9 & 0.7 & 1.4 & 0.5 & base \\
\hline \hline Botton & 10.6 & 40.0 & 0.6 & 1.5 & 0.5 & \\
\hline
\end{tabular}

Structure of investigated alloy is presented by equiaxial b-grains (Figure 9a). Insignificant amount of a- or $a_{2}$ phase is present on the boundaries of b-grains and in the grain body (Figure $9 \mathrm{~b}$ ) in form of microdispersed particles. The alloy also contains small amount of intermetallic $\mathrm{a}_{2}-\mathrm{phase}\left(\mathrm{Ti}_{3} \mathrm{Al}\right)$
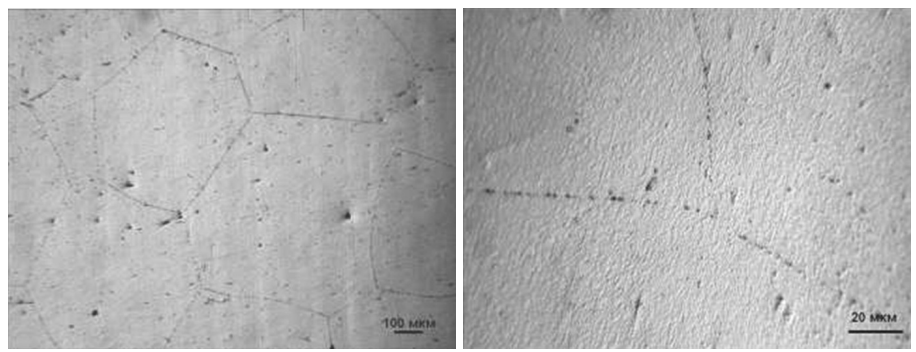

Figure 9. Structure of TiAl system intermetallic with high content of refractory elements

Carried tests of mechanical properties of the samples form Ti-12Al-40Nb-1Mo-2W-0,5Zr intermetallic alloy showed high ductility indices (Table 4).

Table 4. Mechanical properties of TiAl system intermetallic with high content of refractory elements

\begin{tabular}{|c|c|c|c|c|}
\hline № sample & $\sigma_{0,2}, \mathrm{MPa}$ & $\sigma \mathrm{B}, \mathrm{MPa}$ & $\delta, \%$ & $\psi, \%$ \\
\hline 1 & 534 & 555 & 13.3 & 59.9 \\
\hline 2 & 531 & 557 & 12.7 & 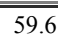 \\
\hline 3 & 517 & 534 & 20.0 & 56.1 \\
\hline
\end{tabular}

Thus, developed technology and carried pilot melts of ingots of TiAl system intermetallic using electron beam cold hearth melting method showed the perspective of application of EMR method for production of quality ingots of titanium aluminide alloyed with refractory elements.

Small amount of boron is added as alloying element to improve the ductility properties of TiAl system intermetallics [13]. Boron rises temperature of transition into single-phase $\mathrm{a}-\mathrm{area}$ and decreases transition temperature from single-phase a into double-phase $\mathrm{a}+\mathrm{b}$ area, i.e. it acts as $\mathrm{b}$ stabilizing element [14].

In electron beam melting it is difficult to add boron into melted TiAl intermetallic. Effect of electron beam heating on boron melting provokes its intensive evaporation as well as spraying and carry-over of the particles at its addition into the charge in form of powder. Therefore, lanthanum hexaboride $\left(\mathrm{LaB}_{6}\right)$ was $\mathrm{used}$ in order to add boron into the alloy in EBM. Besides, addition of lanthanum by this method is also possible. Its addition into alloy also promotes rise of TiAl system intermetallic ductility at hot deformation [15]

E. O. Paton Electric Welding Institute carried out the investigations on production of ingots of intermetallic alloy Ti-29Al-12Nb-2Cr-2Zr with additional alloying by boron and lanthanum in EBM.

The change, consisting of commercially pure titanium, electrolytic chromium, niobium and zirconium was melted at the first stage. The second remelting was carried out with addition of aluminum and lanthanum hexaboride. Lanthanum hexaboride was added in the charge in form of cylindrical briquettes produced by pressing of LaB 6 powder.

As a result of carried experimental melts $165 \mathrm{~mm}$ diam. Ti-29Al-12Nb-2Cr-3Zr-0.3V-0.01La (Figure 10) ingot was produced. 

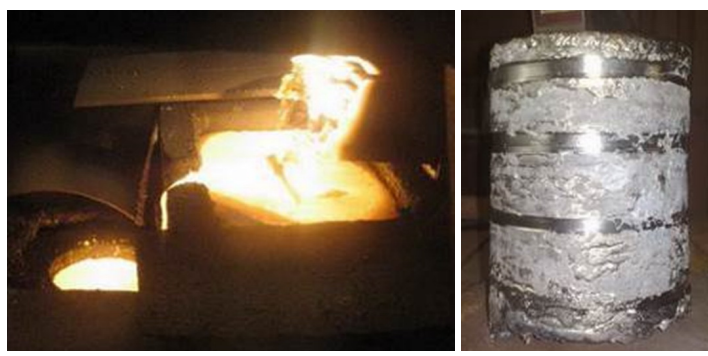

Figure 10. Process of melting and produced $165 \mathrm{~mm}$ diam. Ti-29Al-12Nb-2Cr-3Zr-0.3B-0.01La ingot.

The results of chemical analysis showed uniform distribution of elements on ingot length as well as cross section (Table 5).

Table 5. Composition of $165 \mathrm{~mm}$ diam. titanium aluminide ingot with boron and lanthanum addition

\begin{tabular}{|c|c|c|c|c|c|c|c|}
\hline \multirow{2}{*}{ № sample } & \multicolumn{7}{|c|}{ TiAl intermetallic composition, wt.\% } \\
\hline & $\mathrm{Al}$ & $\mathrm{Nb}$ & $\mathrm{Zr}$ & $\mathrm{Cr}$ & $\mathrm{Ti}$ & $\mathrm{B}$ & $\mathrm{La}$ \\
\hline 1 & 29.4 & 11.8 & 2.9 & 2.6 & \multirow{3}{*}{ base } & \multirow{3}{*}{0.3} & \multirow{3}{*}{0.02} \\
\hline 2 & 28.8 & 12.2 & 3.1 & 2.9 & & & \\
\hline 3 & 29.7 & 11.8 & 2.9 & 2.8 & & & \\
\hline
\end{tabular}

Figure 11 shows a template of ingot from alloy based on double-phase titanium aluminide Ti-29Al-12Nb-2Cr-3Zr-0.3B-0.01La (wt.\%), which solidifies through bphase. It can be seen that fine cast ingot structure is formed from given structure.

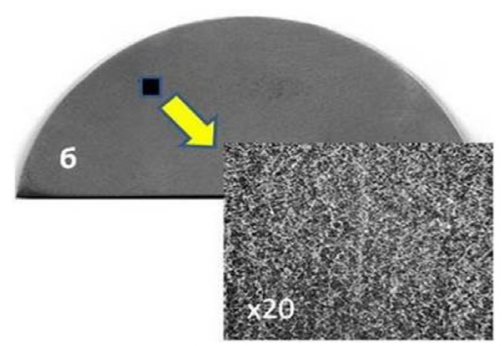

Figure 11. Macrostructure of $165 \mathrm{~mm}$ diam. ingot of Ti-29Al-12Nb-2Cr-3Zr-0.3B-0.01La (wt.\%)

Microstructure of alloy has completely lamellar $\left(\mathrm{a}_{2}+\mathrm{g}\right)$ structure with seldom small areas of g-phase (Figure 12). Also the structure contains rod-like crystals and light dispersed particles presenting themselves titanium boride and lanthanum oxide. The analysis showed that rod-like crystals are enriched with boron and they can be identified as borides and light particles contain lanthanum and oxygen, and they can be identified as lanthanum oxides.
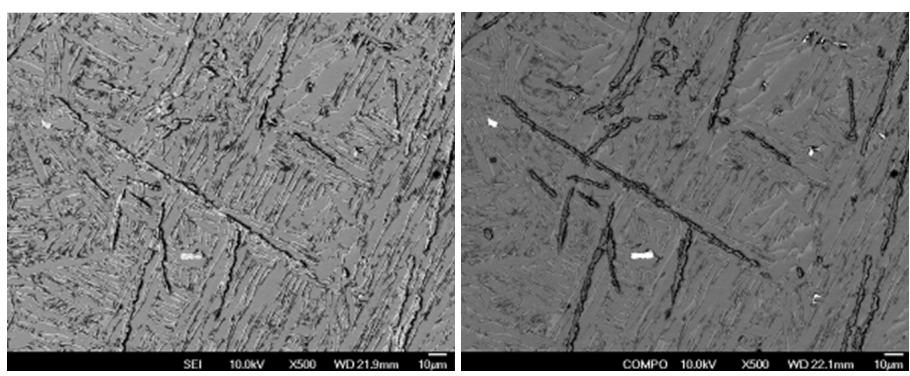

Figure 12. Microstructure of alloy No. 3 Ti-29Al-12Nb-3Cr-3Z-0.3V-0.01La: a - image in the secondary electrons, $b$-image in the back scattered electrons

Further hot deformation treatment of alloyed double-phase g-TiAl modified with boron and lanthanum was carried in two stages. At the first stage the samples were heated in resistance electric furnace to $1220^{\circ} \mathrm{C}$ temperature that corresponds the area of a-phase existence and hold for 40 min. After that, the heated samples were placed between the movable and unmovable punches of hydraulic press and its pressing with deformation level around 50\% took place (Figure 13a). After pressing the sample was placed back into the furnace and heated to temperature below the eutectoid transformation $-1100^{\circ} \mathrm{C}$ with 0.5 hour holding. After that the samples was rolled on a rolling mill with general level of deformation $80 \%$ in two mutually perpendicular directions (Figure 13b). The final thickness of billet made 7 mm. After rolling end the samples were subjected to intermediate heat treatment - heating to $900^{\circ} \mathrm{C}$, holding during 2 hours and cooling with furnace. As a result of two-stage rolling and further mechanical treatment the g-TiAl sample alloyed with boron and lanthanum was obtained. 

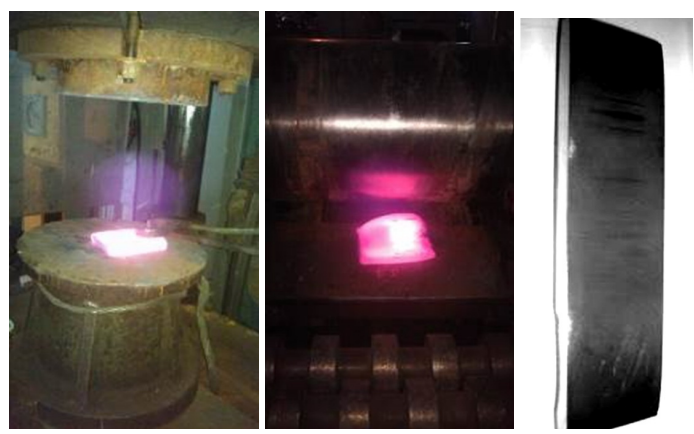

Figure 13. Process of hot deformation treatment of two-phase g-TiAl alloyed with boron and lanthanum.

There are next changes in the sample structure after hot plastic deformation. The structure becomes less relief, size of plates and distance between them are reduced, and rod-like crystals are chipped on separate parts (Figure 14a). The same as in the structure of sample without deformation, here the light dispersed particles are observed over the whole surface (Figure 14b).
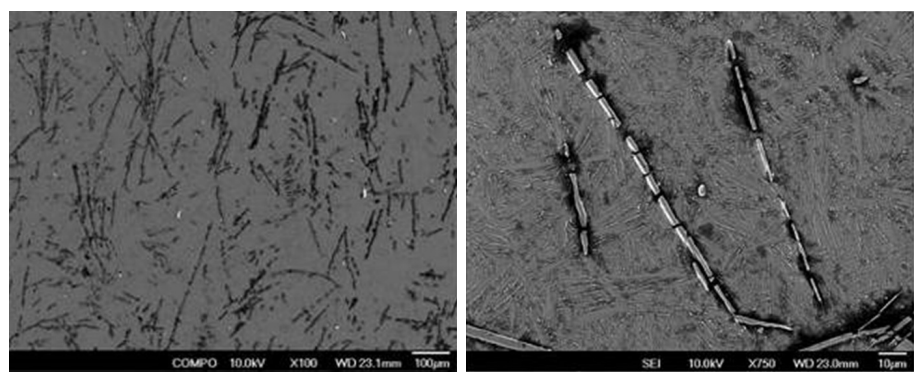

Figure 14. Microstructure of wrought g-titanium aluminide, alloyed with boron and lanthanum: a - image in the secondary electrons, $b$ - image in the back scattered electrons.

After hot deformation treatment, the final heat treatment was carried out. The wrought alloy in vacuum furnace was heated to $1260^{\circ} \mathrm{C}$ and hold for 30 min. Then it was cooled to $900^{\circ} \mathrm{C}$ in the furnace and to room temperature on air. After re-heating to $900^{\circ} \mathrm{C}$ is carried out, holding for 2 hours and cooling with the furnace.

After the heat treatment there is formation of bimodal (duplex) structure, which consists of areas presented by re-solidified grains and areas of lamellar structure. Also, small inclusions of various shapes (Figure 15) are uniformly located over the investigated surface.
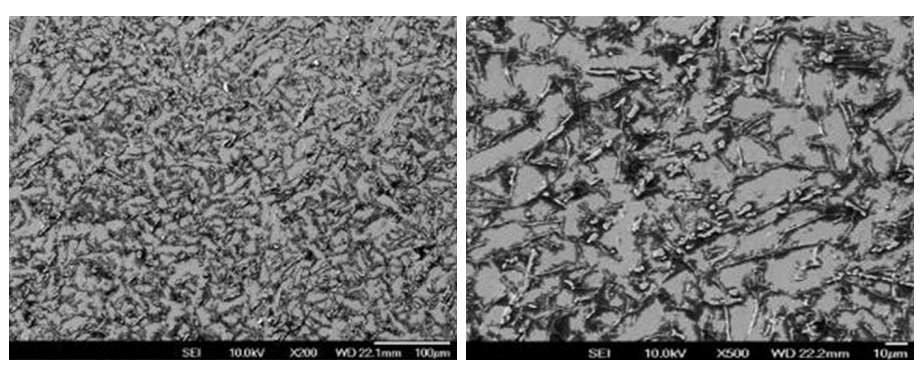

Figure 15. Microstructure of g-titanium aluminide sample alloyed with boron and lanthanum after deformation and heat treatment: $a$ - image in the secondary electrons; $b$ - image in the back-scattered electrons.

Tests of mechanical properties of alloy doped with $0.3 \% \mathrm{~B}$ and $0.01 \%$ La showed high values of yield limit $\mathrm{s}_{0.2}$ for compression (Table 6 ) and for bending (Table 7 ). The samples withstood the tests at $900^{\circ} \mathrm{C}$ and $50 \%$ deformation without fracture.

Table 6. Results of mechanical compression tests of alloy Ti-29Al-12Nb-3Cr-3Zr-0.3B-0.01La

\begin{tabular}{|c|c|c|c|c|c|}
\hline \multicolumn{3}{|c|}{ Yield limit $\sigma_{0,2}, \mathrm{MPa}$} & \multicolumn{3}{|c|}{ Strength limit, $\sigma \max , \mathrm{MPa}$} \\
\hline $20^{0} \mathrm{C}$ & $600^{0} \mathrm{C}$ & $900^{0} \mathrm{C}$ & $20^{0} \mathrm{C}$ & $600^{0} \mathrm{C}$ & $900^{0} \mathrm{C}$ \\
\hline 1078 & 920 & 640 & 1660 & - & 1050 \\
\hline
\end{tabular}

Table 7. Results of mechanical bending tests of alloy Ti-29Al-12Nb-3Cr-3Zr-0.3B-0.01La

\begin{tabular}{||c|c|}
\hline Strength limit $\sigma_{\mathrm{B}}, \mathrm{MPa}$ & Moduls of elasticity $E, \mathrm{GPa}$ \\
\hline $20^{\circ} \mathrm{C}$ & $20^{\circ} \mathrm{C}$ \\
\hline \hline 583 & 155 \\
\hline \hline
\end{tabular}

Thus, the developed technology and carried test melts of ingots of TiAl system intermetallics as well as performed metallographic examinations showed the perspectives of application of EBM method for production of quality titanium aluminide ingots. At that uniform distribution of alloying elements and additives as well as formation of fine grain structure in the ingot is observed. 